\title{
Hughes-Stovin Syndrome
}

Vitor Alves Cruz', Yadine A. Muniz², Pedro Paulo Teixeira e Silva Torres ${ }^{3}$, Kim-

Ir-Sem Santos Teixeira ${ }^{4}$, Jozelia Rego ${ }^{5}$, Nilzio Antônio da Silva ${ }^{6}$

\begin{abstract}
Hughes-Stovin syndrome is a rare disorder of unknown etiology characterized by the association of multiple pulmonary artery aneurysms and deep venous thrombosis. Some authors consider this entity an incomplete form of Behcet's disease due to the similarities between the radiologic and anatomopathological findings of pulmonary involvement. The authors report a case of Hughes-Stovin syndrome whose first venous thrombotic event preceded the development of pulmonary aneurysms by five years.
\end{abstract}

Keywords: Hughes-Stovin Syndrome, pulmonary artery aneurysms and deep venous thrombosis.

\section{INTRODUCTION}

Aneurysms are rare in the pulmonary circulation and, unlike aortic aneurysms, they are more common in young patients. ${ }^{1}$

Approximately half of the cases are associated with congenital cardiovascular defects, especially septal and ductus arteriosus abnormalities. Other less common causes include: syphilis, atherosclerosis, trauma, pulmonary hypertension, and infectious emboli. ${ }^{1}$

When a single aneurysm develops in the pulmonary arteries, the large muscular arteries are usually involved. Multiple aneurysms are rare, but they develop preferentially in the peripheral branches of the pulmonary arteries. ${ }^{2}$

Hughes-Stovin syndrome is a rare condition, initially described in $1959,{ }^{3}$ is characterized by multiple pulmonary aneurysms and deep venous thrombosis. ${ }^{4}$

Signs and symptoms include: cough, dyspnea, hemoptysis, headache, intermittent fever, papilledema, and those related with peripheral thrombophlebitis. ${ }^{5}$

Rupture of an aneurysm inside the airways is the most common cause of morbimortality. ${ }^{5}$
We report a case of Hughes-Stovin syndrome whose first thrombotic event preceded the development of pulmonary aneurysms by five years.

\section{CASE REPORT}

This is a 37-year old male patient seen at the pulmonary outpatient clinic in August 2007 with complaints of thoracic pain on deep inspiration, hemoptoic cough, lack of appetite, and daily fever up to $39{ }^{\circ} \mathrm{C}$, for three months. Two weeks before the clinical appointment, the patient developed edema and severe pain in the left calf.

Upon questioning, the patient reported 9-kg weight loss in one month.

The patient had a history of deep venous thrombosis in the right lower limb in 2002; recurring ulceration in the oral cavity, especially in adolescence; blister in the scrotum evolving to painful ulcer and spontaneous resolution at the age of 17 years.

On physical exam, the patient had good general condition, mucous membranes pale were $(+/ 4+)$, and the patient was

Received on 01/14/2009. Approved on 04/02/2009. We declare no conflict os interest.

Rheumatology Service - Internal Medicine Department - Medical School - Universidade Federal de Goiás

1. Rheumatology Resident (R2) at Hospital das Clínicas - UFG

2. Rheumatology Resident (R1) at Hospital das Clínicas - UFC

3. Radiology Resident (R3) at Hospital das Clínicas - UFG

4. Head of the Pathology, Radiology, and Imaging Diagnosis Department of the Medical School of UFG

5. Coordinator of the Rheumatology Residency Program of Hospital das Clínicas - UFG

6. Rheumatology Professor of the Medical School of UFG

Correspondence to: Rheumatology section. Departamento of Internal Medicine HC/UFG. $1^{\mathrm{a}}$ Avenida, s/n - Setor Leste Universitário. Goiânia, Goiás, Brazil. CEP: 74.605-020. Phone: + 55 (62) 3261-2029. E-mail: vitorcruz@msn.com 
eupneic and acyanotic. Cardiovascular and respiratory systems did not show abnormalities. Pulses were palpable and symmetrical in the lower and upper limbs; swelling of the left calf; negative pathergy. The joints did not show signs of inflammation. Glasgow 15, without sensory or motor deficit on the neurologic exam.

Complementary tests showed: normal CBC; ESR $=106$ $\mathrm{mm}$; renal and liver function tests within normal limits; serologies for HCV, HBV, and HIV were negative; VDL negative; PPD, non-reactive; sputum negative for acid-fast bacilli; blood cultures were negative; ANF, rheumatoid factor, and ANCA negative; anticardiolipin antibodies (IgG and $\mathrm{IgM}$ ) negative; $\mathrm{C}$ and $\mathrm{S}$ protein activity, normal; UA, normal. Doppler of the lower limbs: subacute deep venous thrombosis in the left, and thrombosis of the vena cava distal to the junction with the renal vein. Thorax angiotomography: multiple aneurysms and thrombosis of the pulmonary artery (Figures 1 and 2). Lung biopsy: areas of infarction, alveoli filled with polymorphonuclear cells, and bronchiolitis obliterans and organizing pneumonia (BOOP).

The patient was evaluated at the Rheumatology service, receiving the diagnosis of Hughes-Stovin syndrome. Anticoagulation with enoxiparin and combine pulse therapy with methylprednisolone (1 gram for three days) and cyclophosphamide (1 gram per monthly session) was instituted. The condition of the patient improved considerably with normalization of inflammatory activity tests, and control angiotomography revealed a reduction in the number and caliber of aneurisms. The patient remained stable until the $6^{\text {th }}$ session of monthly combined pulse therapy when he developed hemoptysis associated with rupture of one of the aneurysms. He underwent right pneumectomy with good postoperative evolution.

The patient remains stable, without further episodes of hemoptysis, but he has intermittent hemoptoic episodes. We decided to start immunobiological therapy (anti-TNF). The patient received two infusions of infliximab $(3 \mathrm{mg} / \mathrm{kg} / \mathrm{dose})$ followed by subcutaneous applications every two weeks of adalimumab, $40 \mathrm{mg}$, without intercurrences or episodes of hemoptysis or hemoptoic.

\section{DISCUSSION}

The first cases of the association of venous thrombosis, mural thrombus of the pulmonary artery, and multiple pulmonary artery aneurysms were presented as a discrete pathological entity by Hughes and Stovin in 1959. The eponym "HughesStovin syndrome" was used by Koop and Green in $1962 .{ }^{6}$

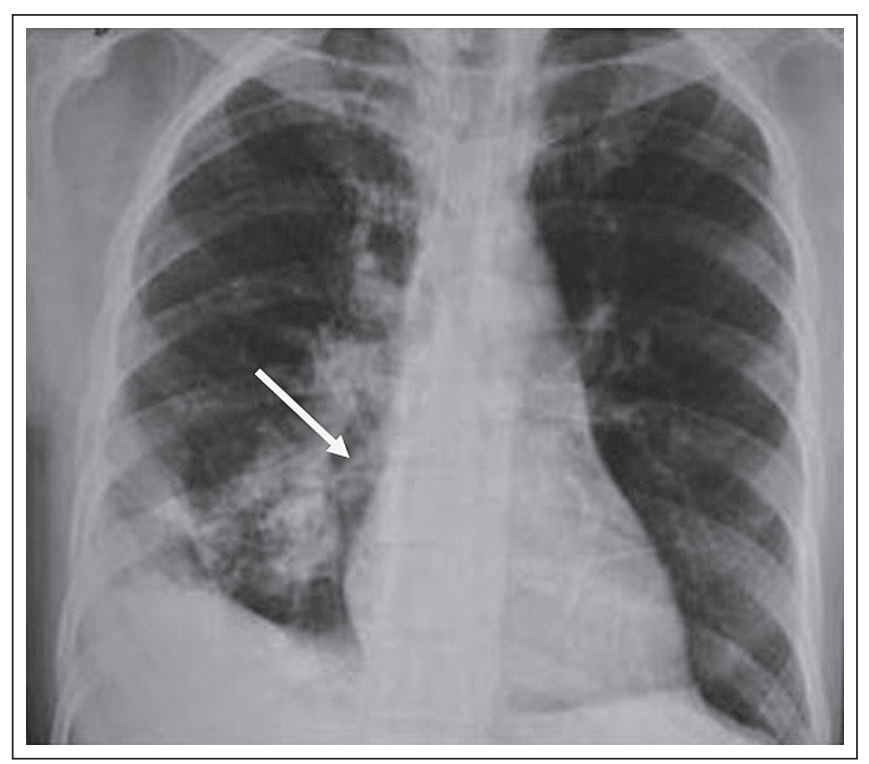

Figure 1. Right perihilar pulmonary artery aneurysm.

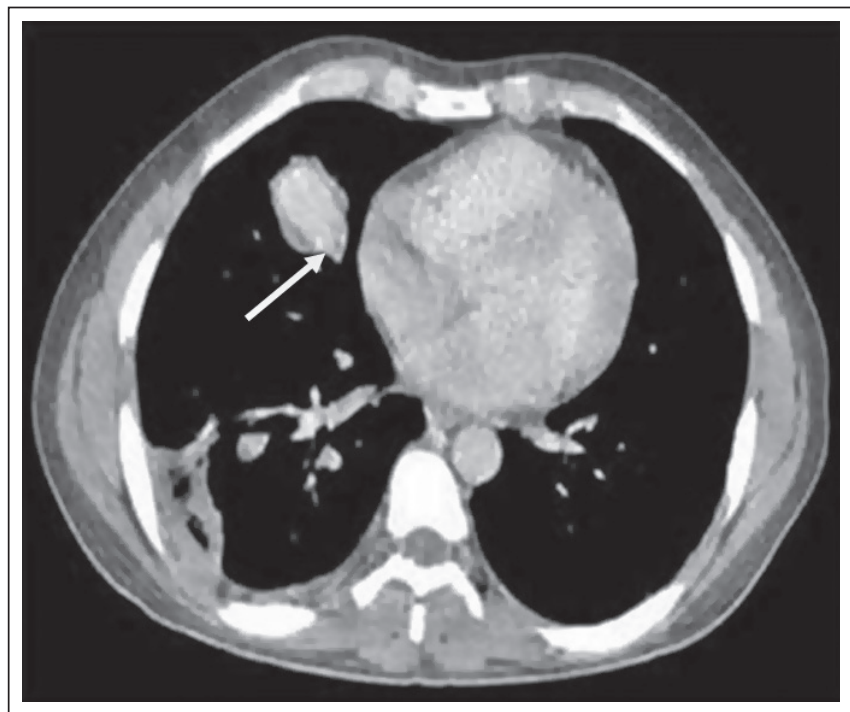

Figure 2. Chest angiotomography: pulmonary artery aneurism and thrombosis.

The typical presentation has three phases: in the first phase, symptoms of thrombophlebitis are seen; the second phase consists on the development of pulmonary aneurysms; and the third stage is characterized by aneurismal rupture causing massive hemorrhage and death. ${ }^{6}$

The etiology of this disorder is unknown, and systemic vasculitis has been suggested. ${ }^{6}$

Since pulmonary embolism rarely causes aneurysms, Hughes and Stovin postulated that congenital or degenerative changes of the bronchial arteries would result in inadequate 
nutrition of the pulmonary arteries, producing a type of embolus different from that seen in normal pulmonary arteries. ${ }^{3,7}$

According to another theory, emboli infected with low virulence organisms could cause mycotic aneurysms. ${ }^{7}$

Some authors have suggested that Hughes-Stovin syndrome is a partial manifestation of Behçet's disease. ${ }^{2}$ Pathological studies on this syndrome have demonstrated, repeatedly, mural thrombus and inflammation, and several reports on the pulmonary manifestations of Behçet's disease have suggested that an intraluminal blood clot in the pulmonary arteries could develop "in situ", secondary to inflammation of the wall of this artery, and not pulmonary thromboembolism - especially in cases without deep venous thrombosis. ${ }^{6}$

Our patient had a history of recurrent oral ulcerations in adolescence, and, initially, the hypothesis of Behçet's diseases was suggested.

Since we did not observe recent oral lesions and the pathergy test was negative, the diagnosis of Hughes-Stovin syndrome was made.

This disorder does not have a standardized treatment. Few cases of this syndrome have been reported. A treatment similar to that used in Behçet's disease, with isolate corticotherapy, or in association with immunosuppressants, has been suggested. The evidence is not very reassuring due to the fatal development of several cases, despite treatment. ${ }^{4}$

Anticoagulation is controversial in the literature. Some authors question the real need of this treatment due to the essentially inflammatory etiology of thrombi, making them to be firmly adhered to the endothelium, minimizing the risks if emboli. The risk of fatal hemoptysis is also associated with this treatment modality, especially in patients who are not treated with immunosuppressants. Anticoagulation is acceptable, as long as it is concomitant with corticotherapy, although controlled prospective studies on the subject do not succeed. $5,6,7$
Our patient showed good evolution after the first combined pulse therapy with methylprednisolone and cyclophosphamide, without further episodes of hemoptoic and with regression in the size and number of pulmonary aneurysms. However, as reported in the literature, he had hemoptoic after the sixth course of pulse therapy, which required new therapeutic discussion.

\section{CONCLUSION}

The diagnosis of pulmonary thromboembolism should be approached carefully in patients with pulmonary artery aneurysms and thrombi along with deep venous thrombosis. This association requires the exclusion of vasculitis, such as Behçet's disease and Hughes-Stovin syndrome.

\section{REFERÊNCIAS}

\section{REFERENCES}

1. Kopp WL, Green RA. Pulmonary artery aneurysms with recurrent thrombophlebitis: the "Hughes-Stovin syndrome". Ann Intern Med 1962; 56:105-14

2. Durieux P, Bletry O, Huchon G, Wechsler B, Chretien J, Godeau P. Multiple pulmonary arterial aneurysms in Behcet's disease and Hughes-Stovin syndrome. Am J Med 1981; 71:736-41.

3. Hughes JP, Stovin PGJ. Segmental pulmonary aneurysms with peripheral venous thrombosis. Br J Dis Chest 1959; 53:19-27.

4. Herb S, Hetzel J, Friedrich J, Weber J. An unusual case of HughesStovin syndrome. Eur Respir J 1998; 11:1191-3.

5. Ammann ME, Karnel F, Olbert F, Mayer K. Radiologic findings in the diagnosis of Hughes-Stovin syndrome. AJR 1991; 157:1353-4.

6. Ketchum ES, Zamanian RT, Fleischmann D. CT angiography of pulmonary artery aneurysm in Hughes-Stovin syndrome. AJR 2005; 185:330-2.

7. Mahlo HR, Elsner K, Rieber A, Brambs HJ. New approach in the diagnosis of and therapy for Hughes-Stovin Syndrome. AJR 1996; 167:817-8. 